\title{
Os impactos do programa comunidade escola sobre a violência entre os jovens ${ }^{13}$
}

\section{Introdução}

Anna Karolina Selhorst Bezerra* Luciano Nakabashi*

A violência é um tema amplamente discutido, e está no centro das questões políticas e econômicas dos grandes centros urbanos, mas pode-se dizer que é um problema generalizado. A solução para esse problema não é simples, posto que não há um diagnóstico preciso sobre suas causas. Várias áreas do conhecimento se dedicaram a estudá-la, surgindo abordagens diferentes e, muitas vezes, divergentes.

A educação, solução para vários problemas, apresenta-se como uma alternativa, almejando o resgate cultural e formação de uma massa crítica. Porém, se faz perceber, cada dia mais, a violência presente no ambiente escolar, violência esta que se desenvolve tanto externa quanto internamente à escola, alterando as relações e dificultando a interação entre os atores principais - professor/ aluno.

Em meio a essas dificuldades e visando o melhor aproveitamento do espaço público, o município de Curitiba implementou o projeto de abertura de algumas escolas municipais nos finais de semana propiciando vários tipos de atividades, sendo este conhecido como Programa Comunidade Escola. Em seus pressupostos estão: interar a comunidade à escola, com maior participação desta em ambientes educacionais e desportivos, a partir do espírito de pertencimento; e melhorar o ambiente escolar através de uma maior inclusão social.

O Programa Comunidade Escola, que teve início em 2005, traz, adicionalmente, o propósito de reduzir os índices de violência. Nesta linha, o presente estudo se propõe a discutir em que medida o Programa teve impactos na redução da violência no município, com enfoque para as escolas participantes e seu entorno.

\section{A violência versus a escola}

De acordo com Charlot (apud Abramovay et al, 2002, p.93), a violência escolar pode ser classificada em três níveis:

$\Rightarrow$ A violência - golpes, ferimentos, violência sexual, roubos, crimes, vandalismo;

$\Rightarrow$ Incivilidade - humilhações, palavras grosseiras, falta de respeito;

\footnotetext{
13 O presente estudo faz parte dos estudos do Núcleo de Avaliação de Políticas Públicas Educacionais da UFPR. * Economista pela UFPR.

** Doutor em Economia e Professor do Departamento de Economia da UFPR. Endereço eletrônico: luciano.nakabashi@ufpr.br
} 
$\Rightarrow$ Violência simbólica ou institucional - falta de sentido de permanecer na escola por anos; o ensino como um desprazer, que obriga os jovens a aprender matérias e conteúdos alheios aos seus interesses; as imposições de uma sociedade que não sabe acolher seus jovens no mercado de trabalho; a violência das relações de poder entre professores e alunos; a negação da identidade e satisfação profissional aos professores, a sua obrigação de suportar o absenteísmo e a indiferença dos alunos.

\subsection{O papel da escola no que tange à violência}

A educação é tida como solução para vários problemas, um fator de mobilidade social e melhores oportunidades. "Soluções educacionais também se encontram na raiz da violência nas escolas, que, conforme dados, têm impacto sobre a sociabilidade, a qualidade do ensino e o aproveitamento dos alunos. Não se pode reduzir tudo à educação, mas fica fora de dúvida o valor das suas contribuições, inclusive para combater a pobreza, questão base, intimamente associada à exclusão" (ABRAMOVAY et al, 2002a, p.11).

$\mathrm{Na}$ solução dessa problemática, devem-se levar em conta tanto as variáveis exógenas - relacionadas ao sistema econômico, a desestruturação familiar, as políticas públicas, etc; quanto as variáveis endógenas - associadas ao grau de organização ou desorganização local, os métodos e padrões de cada escola (LOPES E GASPARIN, 2003, p.303).

No que se refere aos problemas externos à escola, "a escola assume uma série de funções compensatórias às carências trazidas pelos alunos, sobretudo por aqueles provenientes de contextos sociais marginalizados. Portanto, a atratividade da escola pressupõe a transformação dessa instituição em espaço não só de aprendizagem, mas também de sociabilidade para os alunos que a freqüentam" (IPEA, 2005).

Segundo Njaine e Minayo (2003, p.132), a escola tem o papel de mediadora, e cabe a ela, conjuntamente à família, ampliar o diálogo sobre a questão da violência:

A família e a escola têm sido historicamente a bases da educação de crianças, adolescentes e jovens e da inserção social desse grupo. A negação do diálogo, as formas de violência física, sexual, moral e psicológica contra esse grupo etário que ocorrem muitas vezes no âmbito intrafamiliar podem refletir na vida escolar sob a forma de comportamentos agressivos ou mesmo apático dos alunos, desafiando os educadores para o enfrentamento dessa problemática. Diante da violência, o desafio maior é o reconhecimento da complexidade de suas manifestações, sem reduzi-la a uma única fonte. O lugar da escola, como fonte privilegiada de mediação, assim como o da família possibilita uma atuação ampla no campo da prevenção da violência. Mas é necessário que essas instituições caminhem juntas, buscando principalmente estabelecer uma relação respeitosa com os jovens. 
A escola pode transformar situações críticas, através de uma melhor organização de sua didática, onde haja o diálogo, valorização de alunos e professores e sentimento de pertencimento. Também é necessário cultivar vínculos com a comunidade, contar com a participação dos pais dos alunos, abrir as escolas nos finais de semana para atividades sociais, culturais e esportivas, tornando-se, assim, a escola um local seguro e respeitado perante a sociedade. (Abramovay et al, 2002a, p.84)

\subsection{Impactos e conseqüências da violência no ambiente escolar}

O aumento das dificuldades cotidianas tem provocado profundas mudanças na instituição escolar, que provêm tanto de problemas internos de gestão, como de fenômenos exteriores à escola, conflito de valores e desorganização da ordem social (Abramovay et al, 2002, p.78).

No que tange aos problemas internos, podemos verificar um período de mudanças no padrão de violência verificado a partir dos anos 90, englobando, além de atos de vandalismo, práticas de agressões interpessoais, sendo mais freqüentes agressões verbais e ameaças, sobretudo entre o público estudantil (Gonçalves e Sposito, 2002, p.104).

Em pesquisa realizada em 1997, com 52 mil professores dos sistemas públicos de ensino, distribuídos em todo o país, foram identificadas três situações tidas como assíduas: as depredações, furtos ou roubos que atingem o patrimônio, as agressões físicas entre os alunos e as agressões de alunos contra os professores (GONÇALVES e SPOSITO, 2002, p.103).

Conforme Gonçalves e Sposito (2002, p.104), no que tange à prática de agressões interpessoais dentro da escola:

... a pesquisa revelou que o fenômeno varia de intensidade em cada estado da federação. Os maiores índices foram registrados no Distrito Federal, em Brasília (58,6\%), e os mais baixos índices, no Estado de Goiás (8,5\%), ainda que ambos estejam situados na mesma região geográfica. $\mathrm{O}$ estudo registra, também, as agressões dirigidas a professores no interior dos estabelecimentos de ensino. O Estado do Mato Grosso foi o que apresentou o maior índice (33\%), ficando o Estado do Rio de Janeiro com o menor número $(1,2 \%)$ de ocorrências de violência física contra os docentes. Ressalta-se, entretanto, que as práticas de agressão, tanto entre os alunos como contra os professores, são mais comuns em estabelecimentos de grande porte e nas capitais.

Lopes e Gasparin (2003, p.300) referem-se a essas mudanças como incremento nas ações violentas, adicionalmente citam o porte de armas e brigas de gangues no interior das 
escolas, afirmando que "a autoridade da escola, bem como de seu principal representante, o professor, parece não ser mais suficiente para resolver tais problemas e restaurar a "ordem" necessária ao desenvolvimento do trabalho pedagógico." Com isso, surge a necessidade cada vez mais freqüente da força policial.

Essas transformações no âmbito escolar fazem com que se questione a denotação da escola, na qual ela “... aparece, ao mesmo tempo, como causa, conseqüência e espelho de problemas aos quais, muitas vezes, não consegue responder e cuja solução não se encontra ao seu alcance" (ABRAMOVAY et al, 2002a, p.78).

Segundo Abramovay et al, a percepção do que é a escola está se modificando: "Por um lado, a escola é vista como um lugar para a aprendizagem, como caminho para uma inserção positiva no mercado de trabalho e na sociedade, por outro lado, muitos alunos consideram a escola como um local de exclusão social, onde são reproduzidas situações de violência e discriminação (física, moral e simbólica)" (ABRAMOVAY et al, 2002a, p.75).

Njaine e Minayo (2003, p.125), referindo-se à pesquisa ${ }^{14}$ realizada em 2002, apontam para o descaso, relatado por alunos, no meio escolar:

As atitudes distantes e autoritárias dos professores obstrui o diálogo com os alunos e impede a verdadeira orientação. Alguns exemplos citados pelos alunos evidenciaram o comportamento autoritário e agressivo por parte dos agentes responsáveis por sua educação e revelaram a significativa atuação da escola como espaço de mediação da violência, e o poder de transmitir os sentimentos mais positivos e os mais negativos com relação à vida aos adolescentes. Falar palavrões em sala de aula, chamar o aluno de "burro", "ignorante" e tratar com desprezo são algumas das agressões citadas.

A intensificação da violência no ambiente escolar tem aumentado a complexidade da relação professor-aluno, tornando essa relação mais conflituosa. A gestão desses conflitos revelam uma certa "crise" nos padrões tradicionais de ensino (LOPES e GASPARIN, 2003, p. 295).

De acordo com Charlot, a tensão social e escolar produz os incidentes violentos, na qual um simples conflito gera um ato violento. Adicionalmente, afirma que: "Essa tensão é

\footnotetext{
14 Pesquisa Avaliação do Processo de Implantação e dos Resultados do Programa Cuidar, realizada entre os anos de 2000 e 2002, coordenada pelo Centro Latino- Americano de Estudos de Violência e Saúde Jorge Careli, da Escola Nacional de Saúde Pública - Fundação Oswaldo Cruz. A pesquisa foi realizada a partir dos relatos dos alunos da sétima e oitava séries do ensino fundamental e do primeiro e segundo anos do ensino médio, de escolas públicas e privadas de três municípios brasileiros - Iguatu (CE); Juiz de Fora (MG) e Campinas (SP). Também são analisados os depoimentos dos educadores sobre a questão da violência que envolve os adolescentes.
} 
ainda mais forte porque a representação da escola como via de inserção profissional ou social apagou a idéia da escola como um lugar de sentido e prazer" (CHARLOT, 2002, p.440).

"Além das conseqüências subjetivamente estimadas, as violências têm impactos objetivos sobre a qualidade do ensino, na medida em que tendem a provocar uma rotatividade de professores". O corpo docente, em busca de condições mais seguras de trabalho, desconsidera as escolas que possuem maior ocorrência de violência (ABRAMOVAY et al, 2002, p.80).

Em pesquisa realizada pela UNESCO15, em 2001, sobre os efeitos da violência no ambiente escolar, mostra-se que quase metade dos alunos declara que não conseguem se concentrar devido às situações de violência vivenciadas no ambiente escolar. Ainda como conseqüência da violência, temos um segundo grupo expressivo: os dos alunos que afirmam ficar nervosos e revoltados. E um terceiro grupo, menciona a perda de vontade de ir à escola (ABRAMOVAY et al, 2002, p.82).

\section{O programa comunidade escola no município de Curitiba}

Em busca de resultados positivos que podem ser alcançados com a oportunidade de participação da comunidade em ambientes educacionais e desportivos, a partir do 'espírito' de pertencimento, o município de Curitiba implementou o projeto comunidade escola.

O Programa Comunidade Escola, implementado em 2005, tem como objetivo desenvolver ações preventivas e sócio-educativas para contribuir com a inclusão social, melhorar o aprendizado dos alunos, promover a cultura de paz, integrar a comunidade à escola e formar cidadãos (SME, 2007).

\subsection{Quanto à atuação do programa}

“O programa abre as escolas à população nos finais de semana e em horários noturnos, em que não esteja com atividades letivas. Em suas salas de aulas, quadras esportivas, auditórios, bibliotecas e laboratórios de informática, diversas atividades sócioeducativas gratuitas são desenvolvidas nas áreas de saúde, empreendedorismo, cidadania, esporte e cultura" (SME, 2007).

"As atividades são planejadas, em cada escola, por um grupo formado por representantes da comunidade, da escola e da prefeitura, de modo a que sejam observados e

\footnotetext{
15 Pesquisa Nacional Violência, Aids e Drogas nas Escolas, UNESCO, 2001. Realizada em 14 capitais brasileiras, por meio de questionário totalizando 33.655 alunos, 3.099 professores e 10.255 pais.
} 
garantidos os interesses da comunidade. As oficinas são desenvolvidas por voluntários, instrutores, servidores municipais e estagiários de graduação" (SME, 2007).

Em 2006 foram desenvolvidas 6.912 atividades de esporte e lazer (xadrez, futebol, vôlei, capoeira, lutas olímpicas, tênis e Projeto Recicle e Brinque); 3.130 atividades culturais (oficinas de violão, violino, teclado e flauta; Projeto Cinema nos Bairros; oficinas de desenho, dança, música, literatura, coral, apresentações de grupos musicais, cantores locais e grupo folclóricos); no que tange à educação e cidadania foram 2.895 atividades (cursos de informática, curso pré-vestibular, hora do conto, oficinas de inglês, espanhol e latim, oficinas de Gerenciamento de Finanças Pessoais e Declaração de Isenção do Imposto de Renda); 607 atividades na área da saúde (Projeto Ônibus Adolescente Saudável; Projeto Casa Saudável; oficinas de saúde nutricional, aleitamento materno, saúde da mulher), e no enfoque da geração de renda ofereceu 991 atividades como oficinas de artesanato - fuxico, crochê, tricô, bordado, bijuteria, pintura em caixas de madeira e assessórios de miçanga -, cursos de manicuro e pedicuro, pedreiro, porteiro e noções de eletricista (SME, 2007).

\subsection{Metodologia}

A avaliação do Programa Comunidade Escola se estruturou em um estudo quantitativo, do tipo survey, abrangendo o censo das 55 escolas integrantes do programa. Os questionários foram extratificados conforme a idade e sexo, sendo aplicados três questionários para jovens de 15 a 24 anos. Os questionários constituem-se de questões fechadas, que possibilitam a quantificação de um vasto número de informações.

Primeiramente procedeu-se uma estimativa dos estratos de faixa etária e sexo com os dados de participações do mês de Abril de 2007. Uma característica desta amostra é a sua representatividade da população envolvida, que seleciona um indivíduo da amostra com a mesma probabilidade com que seria selecionado da população.

O tamanho da amostra escolhido foi tal que nos permitem inferências com um nível de confiança de $95 \%$ e uma margem de erro de 5\%. O método da amostragem dos participantes foi a construção de uma amostra estratificada por faixa etária e gênero e seleção aleatória dentro destes estratos. O cálculo da amostra considera o estudo da variabilidade entre os elementos do universo, visto que, quanto maior a variabilidade presente nestes elementos maior será o tamanho da amostra a ser pesquisada. Decidiu-se adotar a variabilidade máxima entre os elementos, obtendo-se um valor conservador para o tamanho da amostra em cada segmento. 
Os tamanhos de amostra de cada segmento foram determinados segundo a fórmula a seguir:

$$
\begin{array}{ll} 
& \begin{array}{l}
\text { Sendo: } \\
\text { n o tamanho da amostra, } \\
(N-1) \times D+\frac{1}{4}
\end{array} \quad ; \quad D=\frac{B^{2}}{Z_{\mathrm{a}}^{2}} \quad, \quad \begin{array}{l}
\mathbf{N} \text { o tamanho da população, } \\
\mathbf{Z} \text { o erro máximo e }
\end{array} \\
& \mathbf{Z} \text { o grau de confiança (Bolfarine e Bussab, 2001). }
\end{array}
$$

Os questionários foram aplicados durante os meses de Junho e Julho de 2007 com o apoio de sete pesquisadores de campo e infra-estrutura logística da Unidade Gestora do Programa.

Foi escolhido um grupo de 28 escolas como controle, estas apresentam um perfil sócio-econômico do seu entorno comparável com o grupo de escolas participantes. Foram novamente aplicados questionários para uma mostra representativa de alunos, todos os diretores, um professor a cada escola, assim como uma amostra estratificada por idade e sexo de pessoas na comunidade em torno da escola controle. Foram, então, aplicados questionários para crianças, jovens e adultos.

Apresentado a metodologia, cabe salientar que o presente trabalho selecionou alguns dados da mencionada pesquisa, dado a limitação do tema, sendo assim, a população analisada foram os participantes, ou seja, os beneficiários do programa (crianças, jovens, adultos). Ressalta-se, adicionalmente, que o Programa Comunidade Escola é realizado nas escolas municipais, ou seja, em escolas que vão até a quarta série, embora qualquer pessoa possa participar deste.

\subsection{Análise empírica}

\subsubsection{O papel da escola}

Como salientado anteriormente, a educação é tida como solução para vários problemas. São exemplos: a educação como um fator de mobilidade social, de redução da violência e de criação de melhores oportunidades (ABRAMOVAY et al, 2002).

O papel da escola se torna ainda mais importante em comunidades que sofrem mais com problemas econômicos/financeiros, de desestruturação familiar, de menor grau de alcance de políticas públicas, etc. Desse modo, a escola assume uma série de funções compensatórias às carências da comunidade e dos alunos, ou seja, o papel da escola vai além 
da aprendizagem e também engloba, por exemplo, melhoras na sociabilidade dos alunos que a freqüentam. (IPEA, 2005).

No entanto, como já observado, o aumento das dificuldades cotidianas tem provocado profundas mudança s na instituição escolar, enfraquecendo seu papel não somente no que diz respeito à educação, mas também no que concerne ao seu papel complementar na sociabilidade dos jovens e, desse modo, na redução da violência.

Isso se confirma com os dados apresentados no gráfico 1, onde, na opinião dos jovens participantes do programa, 49\% deles acreditam que a escola tem papel fundamental na determinação da mobilidade social, $27 \%$ acreditam na função de inclusão social e $24 \%$ acham que o seu principal papel é a redução da violência.

\section{Gráfico 1. A opinião dos jovens sobre o papel da escola}

\begin{tabular}{|c|c|c|}
\hline Jovens Participantes \\
\hline $10 \%$ & & \\
\hline freqüência das respostas & $(\mathrm{A})$ & \\
\hline
\end{tabular}

Fonte: Núcleo de Avaliação de Políticas Públicas Educacionais UFPR

Notas: Apenas o grupo de jovens que participa do programa comunidade escola. (A) Fator de sociabilidade/ inclusão social; (B) mobilidade social/ melhores oportunidades de emprego; (C) é responsável por combater a violência através da transmissão de valores e normas sociais.

Assim, a escola não é vista como relevante na redução da violência, justificando a criação de programas alternativos para a redução da violência, como é o caso do Comunidade Escola.

Cabe ainda ressaltar que boa parte dos jovens entrevistados acredita no papel da educação como um fator de mobilidade social. Como retratado por Abramovay et al (2002), essa mobilidade é uma solução para vários problemas sociais.

\subsubsection{O Programa Comunidade Escola}

No que concerne o papel do Programa Comunidade Escola na relação indivíduo escola, $47 \%$ dos jovens participantes acreditam que o Programa melhora o comportamento da 
comunidade, dado que esta desenvolve o sentimento de pertencimento, sendo que 33\% acreditam na melhora da relação do aluno com a escola (Gráfico 2).

Gráfico 2. O impacto do programa no comportamento do indivíduo em relação à escola, na percepção do jovem

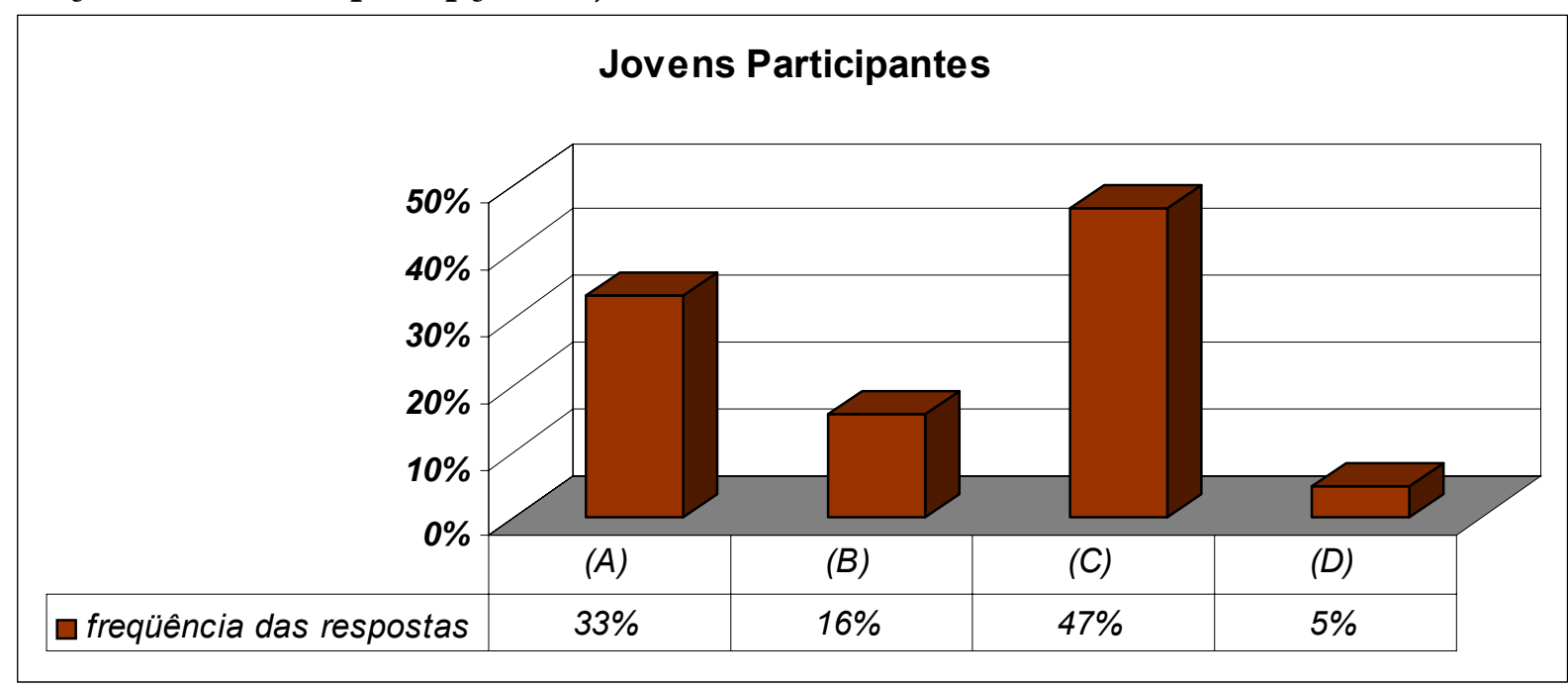

Fonte: Núcleo de Avaliação de Políticas Públicas Educacionais UFPR

Notas: Apenas o grupo de jovens que participa do programa comunidade escola. (A) Melhora a relação do aluno com a escola; (B) melhora a relação do aluno-professor; (C) melhora o comportamento da comunidade, dado o sentimento de pertencimento; (D) não influencia.

De acordo com o gráfico 3, grande parte dos jovens que participam do Programa Comunidade Escola acreditam que o programa tem maior influência na redução da violência.

Gráfico 3. Segundo os jovens, os fatores de maior influência do programa

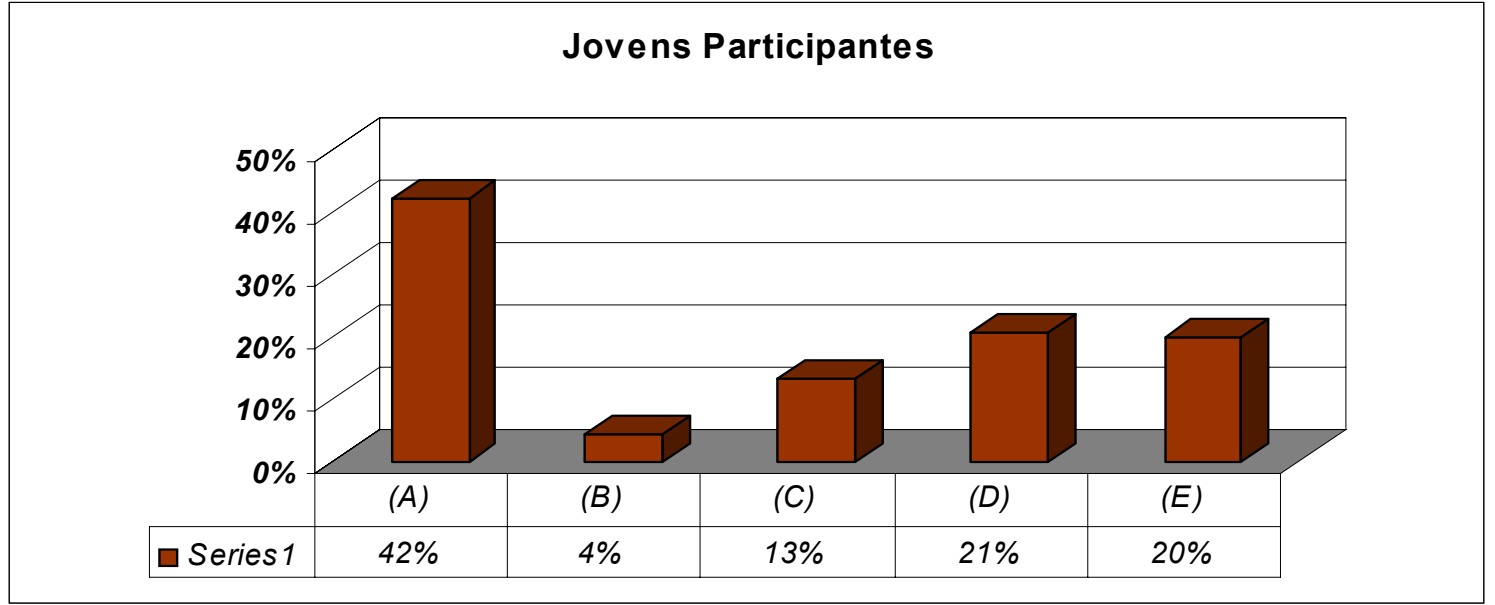

Fonte: Núcleo de Avaliação de Políticas Públicas Educacionais UFPR

Notas: Apenas o grupo de jovens que participa do programa comunidade escola. (A) Redução da violência; (B) redução da depressão; (C) redução do estresse; (D) redução do uso de drogas; (E) redução da degradação dos espaços públicos. 
Comparando as Figuras 1 e 3, pode-se perceber que os jovens participantes confiam mais no Programa do que na escola no que concerne o combate (redução) à violência, sendo um percentual de $42 \%$.

Portanto, existe uma confiança, por parte dos jovens que participam do Programa, de que ele é um elemento importante na melhora da violência na comunidade.

\subsubsection{A Violência na Escola e em seu Entorno}

No que concerne o entorno da escola, a violência entre grupos aumentou nos últimos 5 anos, de acordo com a maioria dos jovens. Considerando que uma diferença de 5\% é estatisticamente significativa, podemos ver pelos dados apresentados no gráfico 4 que a violência aumentou nos últimos cinco anos na percepção dos jovens. No entanto, ela aumentou mais no grupo de jovens não participantes.

Gráfico 4. Violência entre grupos na comunidade, nos últimos 5 ano (percepção dos jovens)

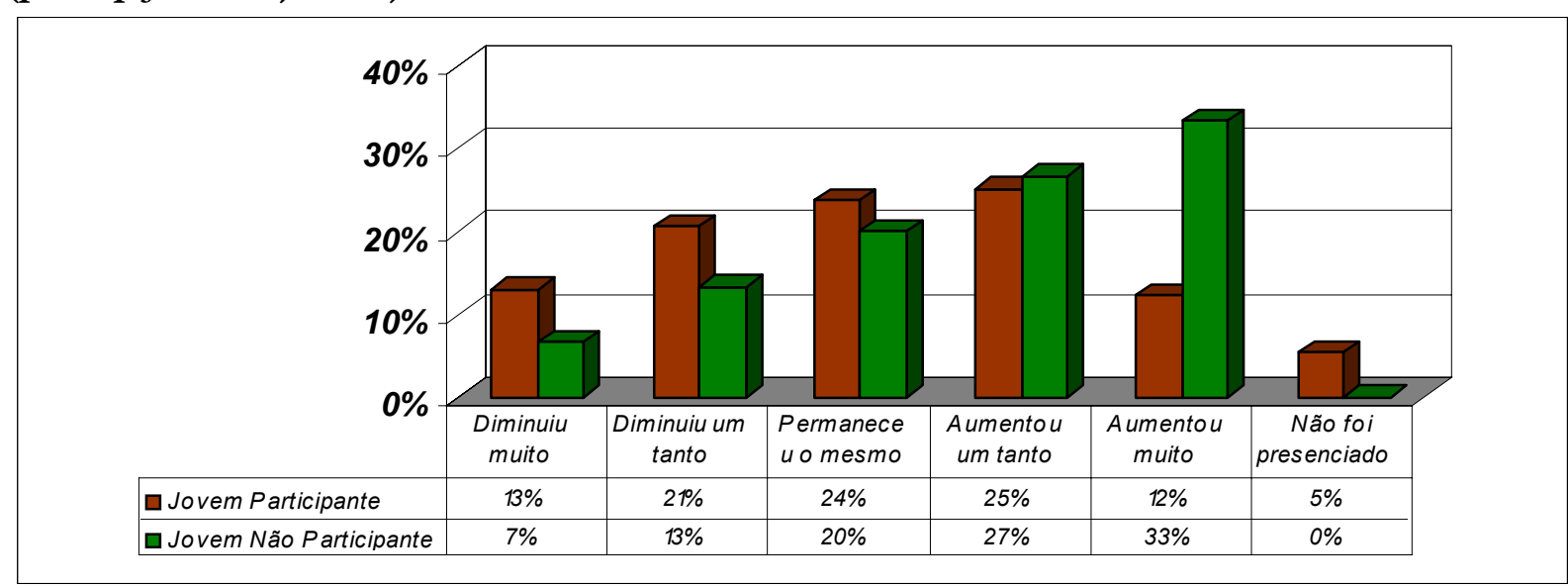

Fonte: Núcleo de Avaliação de Políticas Públicas Educacionais UFPR

Notas: Jovem Participante representa o grupo de jovens que participa do programa comunidade escola; Jovem Não Participante representa o grupo de jovens que não participa do Programa Comunidade Escola

Esse resultado pode ser o efeito do Programa Comunidade Escola gerando um melhor ambiente para os jovens da comunidade.

Como discutido anteriormente, o aumento das dificuldades no cotidiano das escolas, com conseqüências no seu papel de sociabilidade e redução da violência, provocou uma necessidade de novas medidas para conter a violência da escola e na comunidade. De acordo com os dados apresentados no gráfico 3, o Programa Comunidade Escola tem mais eficiência do que a escola nesse quesito. 


\section{Considerações finais}

A partir dos dados selecionados verifica-se que o Programa Comunidade Escola tem um reflexo positivo sobre o comportamento dos jovens participantes.

Os pontos positivos que se pode destacar do Programa, no que concerne à violência, é que ele está presente em comunidades vulneráveis à violência proporcionando atividades educativas em diversas áreas.

Deve-se destacar que apesar do grupo de jovens pesquisados ter relatado um aumento da violência como um todo, os jovens que participam do Programa reportaram em menor freqüência o uso da violência em sua comunidade. O que confirma a afirmação de que o programa impacta melhorando o comportamento da comunidade, dado o sentimento de pertencimento.

\section{Referências bibliográficas}

ABRAMOVAY, M. et al. Escola e violência. Brasília: UNESCO, 2002.

CHARLOT, B. A violência na escola: como os sociólogos franceses abordam essa questão. Sociologias, Porto Alegre, n.8, p.432-443, jul./dez. 2002

GONÇALVES, L.A.O.; SPOSITO, M.P. Iniciativas públicas de redução da violência escolar no Brasil. Cadernos de Pesquisa, n. 115, p. 101-138, mar. 2002

IPEA. Radar Social. Disponível em :<http://ipea.gov.br $>$ Acesso em: 15 set. 2007.

LOPES, C.S.; GASPARIN, J.L. Violência e conflitos na escola: desafios à prática docente. Acta Scientiarum: Human and Social Sciences, Maringá, v.25, n.2, p.295-304, 2003.

NJAINE, K.; MINAYO, M. C. S. Violência na escola: identificando pistas para a prevenção. Interface - Comunic, Saúde, Educ, v.7, n.13, p.119-134, 2003.

RISTUM, M.; BASTOS, A. C. S. Violência urbana: uma análise dos conceitos de professores do ensino fundamental. Ciência \& Saúde Coletiva, Salvador, v.9, n.1, p.225-239, 2004.

SME. Programa Comunidade Escola. Disponível em: <http:// www.cidadedoconhecimento.org.br> Acesso em: 20 ago. 2007. 
